\title{
La responsabilidad social en la industria farmacéutica del estado Zulia
}

\author{
Urdaneta, Mary Josefina*
}

\section{Resumen}

El objetivo de esta investigación fue describir los elementos de responsabilidad social presentes en la industria farmacéutica del estado Zulia. El tipo de investigación fue descriptiva, utilizándose como población la industria farmacéutica inscrita en la Cámara de Industriales del Estado Zulia. La técnica de recolección de datos fue el cuestionario auto-administrado. Los resultados indicaron que existen importantes evidencias de presencia de elementos de responsabilidad social en la industria farmacéutica principalmente en su relación con los grupos de interés internos y éstos están orientados a la salud ocupacional de las empresas. Sin embargo, en cuanto a la manera como se relacionan las empresas con su grupo de interés externo evidencian la presencia de pocos elementos, mostrando debilitadas estas relaciones desde la perspectiva de la responsabilidad social. Es necesario que las empresas fortalezcan estas relaciones, ya que la responsabilidad social, no puede ser entendida solo desde la perspectiva interna de la empresa, va mucho más allá, y si bien existe un importante avance en este ámbito es necesario que se incorporen a las prácticas de responsabilidad social a estos grupos tan importantes para el desarrollo de la empresa y las comunidades.

Palabras clave: Responsabilidad Social, Grupos de Interés, Industria Farmacéutica, Stakeholders.

\section{Social Responsibility in the Pharmaceutical Industry in Zulia}

\begin{abstract}
The objective of this study was to describe the social responsibility elements present in the pharmaceutical industry in the State of Zulia. The research was descriptive, using the population of the pharmaceutical industry registered with the Industrial Chamber in the State of Zulia. The data-collection

Recibido: 28-10-06. Aceptado: 14-11-07

Licenciada en Contaduría Pública. Magíster en gerencia de empresas, mención: Gerencia Financiera. Profesora de de la Facultad de Ciencias Económicas y Sociales de la Universidad Del Zulia, en las cátedras de Investigación de Operaciones y Contabilidad de Costos I. Profesora de Postgrado de la Facultad de Economía de los Talleres de Seminario de Investigación I y II. E-mail: maryjudta@cantv.net
\end{abstract}


La responsabilidad social en la industria farmacéutica del estado Zulia

Urdaneta, Mary Josefina

technique was the self-administered questionnaire. Results indicated that significant evidence for the presence of social responsibility elements exists in the pharmaceutical industry, principally in its relation to internal interest groups and those oriented toward occupational health in the companies. Nevertheless, in terms of the way these companies relate to their external interest group, few elements were in evidence, indicating that these relationships were weakened from a social responsibility perspective. Companies should strengthen these relationships, since social responsibility cannot be understood only from a company's internal perspective, but extends far beyond this; and if a significant advance has been made in this area, it is necessary that social responsibility practices be incorporated into these groups that are so important for development of the company and the communities.

Key words: Social Responsibility, interest groups, pharmaceutical industry, stockholders.

\section{Introducción}

En la actualidad las empresas requieren de un buen entendimiento de la sociedad, no sólo en términos de producción, sino también requiere de una experiencia de vida social, como lugar de aprendizaje, como expresión de acciones filantrópicas y de responsabilidad social. Las preocupaciones sociales no son nuevas en el mundo de los negocios, ya desde el siglo XIX en Europa y Estados Unidos algunos empresarios sobresalieron por sus preocupaciones sobre la sociedad, la vivienda y la caridad hacia sus trabajadores y familiares. Con el advenimiento del siglo $\mathrm{XX}$ y sobre todo con el desarrollo del Estado del bienestar, el espíritu de la caridad y la filantropía se canalizó mediante relaciones más formales y estructuras institucionales. En el siglo XXI los empresarios son más sensibles y receptivos ante las demandas de la sociedad. No se puede olvidar que el fin de las organizaciones es sin duda un "fin social", al proporcionar a la sociedad bienes y servicio de calidad, con apego a lo ético, sin olvidar los problemas sociales del entorno.

De los resultados de la combinación entre los intereses de los empresarios y las necesidades de las comunida- des nace la responsabilidad social empresarial, tema muy debatido en el ámbito mundial; poco desarrollado en Venezuela. Bajo el concepto de responsabilidad social late una orientación de ética normativa que subraya la preocupación por la dimensión social de la actividad empresarial. Es así, como el tema de la ética ha cobrado gran relevancia en los últimos tiempos, cada día se hace más apremiante la incorporación de lo ético en el mundo de los negocios, pues la propia realidad económica empresarial y la sociedad lo demanda de algún modo.

Uno de los sectores más comprometidos con los temas sociales, es el sector farmacéutico. La importancia clave de esta industria radica en su contribución al logro de mejores condiciones de vida a la población, teniendo una inmensa responsabilidad social la cual no puede manejarse a un nivel secundario.

Un aspecto muy importante a destacar del sector, es lo referente a los precios de los medicamentos, que el consumidor se ve obligado a pagar sin alternativas, por su dependencia del récipe médico, privando una aparente óptica cortoplacista de muchos fabricantes de medicamentos, lo cual contradice la responsabilidad social inherente al ámbito 
de acción de la industria y el logro de mejores condiciones de vida para la población. Esto conlleva a que la industria farmacéutica sea cada vez más compleja, obligada a dar respuesta a las demandas de los grupos de su influencia.

La industria farmacéutica venezolana destaca por la inexistencia de Investigación y desarrollo (I\&D) de nuevas drogas, los pocos programas existentes no están orientados hacia objetivos industriales determinados, las posibles explicaciones giran en torno al tiempo, dinero y esfuerzo que deben dedicar a tales actividades.

Uno de los compromisos del sector es el de lograr mejores condiciones de vida para la población, a través de la reestructuración o preservación de la salud y alivio de los síntomas de muchos padecimientos, objetivo que sólo es posible con la existencia de programas de I\&D e innovación, lo que representa su gran responsabilidad social, lo cual la hace una actividad económica con características especiales muy propias.

Por lo antes expuesto, esta investigación se centra en describir los elementos de responsabilidad social presentes en la industria del sector farmacéutico de la región zuliana.

En atención al método, la investigación se orienta hacia el diseño de campo, ya que la recolección de datos primarios se realizó directamente de la realidad donde ocurren los hechos. El tipo de investigación que se utiliza es la descriptiva y el diseño de la investigación el no experimental. La técnica de recolección de datos fue el cuestionario auto-administrado tipo escala utilizando la escala de medición tipo Lickert.

\section{Responsabilidad Social}

El tema de la responsabilidad social atrajo poca atención en los años 60 . No obstante, movimientos activistas de ese tiempo comenzaron a examinar el singular objetivo de las empresas de negocios. Preocupándose por la discriminación a las mujeres y a las minorías y por la falta de legislación que regularan algunas de las actividades industriales que resultaban contaminantes para el ambiente.

Sin embargo, en 1962 Milton Friedman apuntaba que "La responsabilidad social de la empresa es incrementar su beneficio"; atendiendo a la ley y la costumbre ética. En un primer momento se asumió este criterio, sin embargo las nuevas realidades económicas, políticas y sociales han conducido a una definición más amplia de qué se entiende por responsabilidad social empresarial.

Es así como, desde el inicio de la década de 1970, el significado de la responsabilidad social cambió de un modo radical, de tal forma que se pueden encontrar diferentes enfoques, según la época en que se desarrollaron (Fundema, 2004):

a) El primero es el libertario, también conocido por enfoque económico, el cual sostiene que la preocupación primera y última de la empresa es el de obtener utilidades para sus accionistas, en donde la colocación de recursos se hace de manera práctica para responder ante sus accionistas; es decir, maximizar las utilidades de la empresa para responder financieramente ante estos. Este enfoque coincide con lo planteado con Fridman en 1962, sobre que la responsabilidad 
social de la empresa, era la de incrementar los beneficios para sus accionistas.

b) un segundo enfoque, es el modelo del interés propio (self-interest) o también conocido como enfoque económico social, el cual sostiene que las acciones socialmente responsables que lleven a cabo los empresarios recibirán una contrapresentación por parte de la sociedad en determinadas circunstancias. Esto implica que una empresa socialmente responsable tendrá apoyo de la sociedad si los empleados, los clientes y las personas en general tienen una opinión favorable de la empresa. Al observar la sociedad un comportamiento social por parte de la empresa; esto le asegura a la empresa una permanencia mayor en el mercado y mejores utilidades.

c) el tercero, es el enfoque de la moral personal, que es uno de los métodos utilizados por los teóricos para la determinación de la responsabilidad social empresarial, la cual consiste en el análisis de la estructura y la naturaleza de la corporación en si misma;

d) y el cuarto, es el de los grupos de interés, el cual establece que la obligación de la empresa no está limitada a los accionistas, sino que comprende a un grupo más amplio denominado "stakeholders" o públicos interesados, quienes son todas las personas y/u organizaciones que son impactados por la empresa, y las que pueden impactar a la empresa, ya sea negativa y/o positivamente. Este último enfoque, es que aborda esta investigación para describir los elementos de responsabilidad social, presentes en la relación de las empresas del sector con los grupos de interés internos y externos.

Se observa como el concepto de la responsabilidad social, ha evolucionado ampliando en cada una de sus etapas su campo de acción; pasando de posturas minimalistas que reduce la responsabilidad de la empresa a la obtención de beneficios, siendo los accionistas los únicos beneficiados, frente a esta postura la teoría de los Stakeholders amplía el ámbito de responsabilidad de la empresa a otros grupos implicados en sus operaciones, concibiendo un nuevo concepto de empresa con base ampliada donde la empresa se le están demandando cada día más cosas y a los directivos exigiendo un "plus" gerencial, que atienda al largo y al corto plazo y a los objetivos financieros, al paso que se preocupan de los sociales.

En este sentido, el concepto de responsabilidad social en la última década se ha desarrollado en todo el mundo, como respuesta a los grandes cambios producidos. En los países desarrollados los gerentes de empresas comenzaron a discutir acerca de responsabilidad social en los negocios y a desarrollar algunos planes en respuesta a problemas de índole social. Así como también algunas escuelas de administración de empresas implementaron cursos relacionados con la función socioeconómica de la empresa y la ética en los negocios.

Además, las empresas son participes de la responsabilidad en sus actuaciones, por sus políticas o la carencia de las mismas, por sus sistemas de dirección y por una serie de costumbres y vicios empresariales que le alejan de una actuación responsable que mida la con- 
secuencia de sus actos. La responsabilidad o la no responsabilidad, es parte de la cultura de una empresa.

Es importante mencionar que la responsabilidad es una propiedad inherente a la libertad, es la capacidad del hombre de autodeterminarse, de asumir la dirección de su vida y de ejercer esta capacidad en una acción concreta, lo determina como hombre libre y en cuanto libre responsable de los actos que de él se derivan. Al tal punto es relevante la relación entre libertad y responsabilidad, que el hombre será responsable en la medida en que sea libre.

Afirma Jonas (1995) la responsabilidad tiene una condición causal. El agente que responde por sus actos es considerado responsable de las consecuencias, en un sentido jurídico, no un sentido propiamente moral. El daño causado debe ser reparado, y eso aunque la causa no fuera un delito, aunque la consecuencia no tuviera prevista ni querida intencionalmente. Eso sólo ocurre cuando se da una estrecha conexión causal con el acto, de modo que la atribución sea inequívoca y la consecuencia no se pierda en lo imprevisible. Sin embargo la responsabilidad obligada a pagar los daños puede estar libre de toda culpa, en principio de impunidad queda salvaguardado en la relación por virtud de la cual el superior reúne en su persona de manera general la causalidad de sus subordinados.

En este sentido, se mezcló con la idea de la compensación legal la idea de castigo; esta idea tiene un sentido moralmente culpable el acto causal. Según Jonas (1995), cuando se trata de un crimen se castiga más el acto que las consecuencias, y la sanción se mide por el acto; la conspiración para cometer un crimen pero que quedó sin consecuencias es un crimen y es punible, la pena que aquí se impone no sirve para reparar un daño, sino para restablecer el orden moral perturbado, es decir, aquí es la cualidad del acto y no su causalidad el punto decisivo del que hay que responder, sin embargo sigue siendo condición el poder al menos potencial.

La indicada distinción entre responsabilidad legal y responsabilidad moral, se refleja en la sociedad en la distinción entre el derecho civil y el derecho penal, en la evolución de esos dos derechos fueron desmezclados los conceptos inicialmente mezclados de compensación y castigo.

En consecuencia, asevera Jonas (1995:162), que "ambos derechos tienen en común que la responsabilidad se refiere a actos hechos y que adquieren realidad en el hacer desde fuera responsable alguien por lo que ha hecho". Para el autor la responsabilidad así entendida no pone fines, sino que es la carga formal que pesa sobre toda acción causal y que dice que puede pedirse cuentas de ellas; el sentimiento anterior o posterior que se identifica con la responsabilidad es ciertamente moral, pero en su pura formalidad, señala el autor que "no puede proporcionar el principio afectivo para la teoría ética; ésta tiene que ver desde el comienzo hasta el final con la presentación, acreditación y motivación de los fines positivos orientados al bonun humanun".

Ahora bien, cuando se habla de responsabilidad es necesario distinguir entre lo que se denomina responsabilidad interna y lo que se denomina responsabilidad exigible. La responsabilidad interna, cono- 
La responsabilidad social en la industria farmacéutica del estado Zulia Urdaneta, Mary Josefina

cida en ingles con el término responsibility, se refiere aquello por lo cual una persona se siente internamente responsable, e involucra juzgarse a si mismo con relación a sus propios ideales; mientras que la responsabilidad exigible, en ingles accontability, alude a la rendición de cuentas, que una persona debe hacer a otra debido a una obligación o compromiso asumido (Schavartein, 2002).

Ambos términos son caras de la misma moneda, el primero pone de relieve la dimensión interna del concepto de responsabilidad social y el segundo su dimensión externa. El adjetivo social se refiere a una característica de las relaciones humanas. A partir de estas consideraciones se debe distinguir dentro del concepto de responsabilidad social de una organización, la responsabilidad interna y la exigible. La primera referida a la responsabilidad que la organización tiene hacia sus integrantes y los miembros de su comunidad, mientras que la segunda es aquella que le es exigible y por la cual debe rendir cuentas frente alguien que tiene autoridad para exigir su cumplimiento (Bonomi et al., 2003).

Así pues, la responsabilidad social empresarial es parte de una nueva tendencia que busca modernizar y perfeccionar la manera de hacer negocios, mediante el compromiso de contribuir al desarrollo sostenible. Esta nueva visión empresarial incorpora los diferentes ámbitos del proceso de toma de decisiones en las empresas, a saber: El respeto por los valores éticos, El cumplimiento de requerimientos legales, El respeto hacia la gente, el respeto a las comunidades y el medio ambiente.
Por tanto, la responsabilidad social empresarial es la preocupación de los negocios, por el bienestar de la sociedad en su conjunto. Supone un conjunto de obligaciones que están más allá de las establecidas por la ley. En esta definición conviene destacar dos puntos en particular: en primer lugar que la responsabilidad social es voluntaria. Las acciones benéficas impuestas por la ley, como el control sanitario de fábricas, que contaminan al aire y al agua no son voluntarias. En segundo lugar que las obligaciones de la Responsabilidad Social son muy amplias. Rebasan el solo marco de los accionistas de una empresa, pues tiene que ver también con los trabajadores, proveedores, consumidores y comunidades (Gitman, 1995).

De acuerdo con lo expresado, en la responsabilidad social se combinan aspectos legales, éticos, morales y ambientales, y es una decisión voluntaria, no impuesta, aunque exista cierta normatividad frente al tema. Orientar los esfuerzos de la empresa solamente a producir resultados basados en las teorías de producir y vender más con el mínimo costo sin importar el impacto social, es a lo largo del tiempo, el peor negocio del sector productivo que busca la rentabilidad. La estrategia actual y sus esperados beneficios, con dicha posición, puede ser mañana el motivo de su fracaso (Ortiz, 2006).

No obstante, no se puede olvidar que el enfoque de una empresa con base ampliada involucra grupos internos y externos; los primeros orientados a los colaboradores o el equipo de trabajo, sus asociados y accionistas; y los segundos, los externos a clientes, proveedores, familia de los trabajadores, la vecindad y el en- 
torno social, entre estos el medio ambiente. En este sentido, la responsabilidad social empresarial propiamente entendida, no es un número de grandes obligaciones ajenas a la empresa, sino su razón de ser. Según Gismera y Vaquero (2000) las empresas no sólo tienen deberes con sus accionistas, sino con toda la sociedad y no se puede decir que tenga un único objetivo (incrementar los beneficios), sino muchos a los que hacer frente.

En consecuencia, la responsabilidad social empresarial es una obligación hacía la sociedad asumida por las empresas. La empresa socialmente responsable maximiza sus efectos positivos sobre la sociedad y minimiza sus efectos negativos. Estas responsabilidades sociales pueden ser catalogadas según Bateman (2001): las responsabilidades económicas de los negocios son producir bienes y servicios que la sociedad quiere a un precio que perpetúe el negocio y satisfaga sus obligaciones con los inversionistas; las responsabilidades legales son cuando menos la obediencia de las leyes locales, estatales, nacionales e internacionales importantes; las responsabilidades éticas incluye el cumplimiento de otras expectativas sociales no consignadas en la ley. Como tal la ética es una dimensión de responsabilidad social, y las responsabilidades voluntarias son comportamientos adicionales y actividades que la sociedad halla deseable y que dictan los valores de la empresa. Algunos incluyen el apoyo a proyectos comunitarios y contribuciones caritativas.

En concordancia con lo expresado anteriormente EI Libro Verde de la Unión Europea (2001), destaca algunas características sobre Responsabilidad Social de las cuales Cortina (2003), señala dos de las más destacadas: La responsabilidad social sería la integración voluntaria por parte de las empresas de las preocupaciones sociales y medioambientales en sus operaciones comerciales y sus relaciones con los interlocutores. Se relaciona con las responsabilidades voluntarias. Una apuesta de innovación por parte del sector empresarial, especialmente en aquellas empresas que buscan ir más allá del beneficio económico, ofreciendo contenido ético y respeto a los derechos humanos de los actores internos y externos. En esta característica se unen las responsabilidades éticas y económicas.

Así, la responsabilidad social de la empresa está enfocada en sus prácticas respecto a terceros, tales como clientes, competidores, gobierno empleados, proveedores y acreedores, es decir, partiendo de la duda ética de qué hacer frente a una situación determinada, a pesar de la carga negativa que esta situación implique, conseguir aplicar el máximo bien para todos los sectores involucrados a partir de análisis desde la óptica de la virtudes humanas. La responsabilidad social empresarial puede entonces ser abordada desde la perspectiva de lo que Parada (2003) denomina el "triangulo de la justicia ética".

Este triangulo de justicia ética para el caso del administrados financiero, es un campo propio de ayuda para tener una mayor claridad entre la unión de la ética y las finanzas. En este sentido, el concepto de justicia desde el punto de vista de la responsabilidad social está basado en el equilibrio que debe existir entre los derechos de las personas o comunidades y los deberes que deben afrontar respecto 
La responsabilidad social en la industria farmacéutica del estado Zulia Urdaneta, Mary Josefina

a esos derechos las empresas. Así, la justicia general se entiende como aquella parte que un particular cualquiera le debe a la comunidad de personas con la cual habita; la justicia distributiva es lo que la comunidad se debe a los particulares y la justicia conmutativa es lo que se deben los particulares entre si (Parada, 2003). Desde el punto de vista de las finanzas estos tres tipos de justicia están presentes en todas las acciones de la empresa.

Desde la óptica de justicia general o legal, o sea los que las empresas le deben a la comunidad, se pueden presentar diferentes situaciones. Según Parada (2003: 22), algunos actos y relaciones de este tipo de justicia son las siguientes: a) Cumplimiento y establecimientos de impuestos a las utilidades e impuestos personales; b) Niveles de contaminación por algún proyecto. Esto desde el punto de vista de la responsabilidad social debe llevar a considerar por parte de la empresa un probable egreso que esa contaminación pudiera generar. Informar inadecuadamente a la comunidad o inducir a la comunidad a que piense de buena forma de la empresa, cuando la realidad es otra. Ejemplo, falsear estados financieros. Otra situación que se puede generar, según el autor es c) usos de bienes públicos gratis. Desde el punto de vista de la responsabilidad social debe plantearse la forma de cómo hacer una redistribución a la comunidad, considerándose un probable egreso en el flujo de futuras inversiones; d) retribuciones de la empresa cuando la comunidad ha entregado exenciones de pago de impuestos, esto desde la perspectiva de la responsabilidad social, se pueden transformar en egresos de los flujos operacionales; e) Retribución a la comunidad cuando la empresa ha originado daños ecológicos. Éstos deben ser considerados de alguna forma, como egreso de flujos operacionales de una inversión futura. f) Remuneraciones de acuerdo no sólo con el mercado laboral sino que permitan una manera digan de vivir para los trabajadores. g) Pago de externalidades originadas por la empresa a la comunidad, lo que implica el compromiso ético de calcular una evaluación de estas externalidades y considerarlas en los egresos de los flujos a través de compensaciones. h) Contratación de seguros por catástrofes, accidentes u otros probables errores de la empresa que afecta a la comunidad donde la empresa desarrolla sus actividades.

En el caso de la justicia distributiva, o sea lo que la comunidad le debe a los particulares, asevera Parada (2003) también se presentan varios casos en donde la gestión financiera debe tener una participación activa, especialmente cuando la empresa recibe un beneficio particular por estar ubicado en esa comunidad, que se traduzca en aumento en los flujos operacionales, puede originar un efecto ético de la empresa en cuanto a considerar alguna redistribución a la comunidad que tenga impactos positivos para ambos.

Asimismo, según Parada (2003) en el caso de la justicia conmutativa, es decir, las relaciones de la empresa con los grupos de interés externos (proveedores, clientes, competidores). Expresa el autor que el actuar con justicia conmutativa se puede dar, entre otros en los siguientes casos: a) Cobrar altos intereses en las ventas a créditos; b) Aprobar normas contables internas de la empresa para no reflejar apropiadamente los resultados de 
un ejercicio; c) Establecer políticas de precios de ventas artificialmente más bajo que el mercado, para llevar a la quiebra a algún competidor, protegiendo esta pérdida con precios más altos en otros productos; d) Aprobar presupuestos operacionales sabiendo que no es posible empujar los déficits. Aquí se debe analizar políticas alternativas de financiamiento; e) No entregar información económica financiera completa a los dueños de la empresa o a los accionistas; f) No honrar oportunamente sus obligaciones, de acuerdo con lo pautado a sus proveedores bancos teniendo liquidez necesaria para hacerlo; g) Obligar a una quiebra de la empresa de manera fraudulenta, no respetando el derecho de los acreedores, a través de la extracción o liquidación previa de activos; h) No entrar en operaciones de inversiones especulativas, especialmente en mercados financieros, sin tomar los resguardos apropiados; i) Establecer políticas de cobranzas de créditos respetando el derecho de los clientes y no hacerlo a través de políticas de presión por medios poco éticos.

En concordancia con lo anterior, Kliksberg (2003) afirma que la responsabilidad social quiere decir juego limpio con los consumidores, con los empleados, condiciones laborales dignas, con el medio ambiente que es fundamental, es un pilar del desarrollo sustentable y por tanto dentro sus funciones deben impulsar el marco ético para establecer un ambiente que propicie el cumplimiento de las normas jurídicas y la cooperación y entendimiento, entre los accionistas, socios, clientes, proveedores y trabajadores de la empresa. Debe ser concebida como un amplio programa integrado de justicia -ética que se refiere según Parada (2003) a "dar a cada uno lo suyo", que como todo concepto ético es cualitativo, pero tiene importantes implicaciones cuantitativas.

\section{Beneficios y ventajas de la responsabilidad social empresarial}

La responsabilidad social no es una actitud filantrópica que arroja beneficios solo hacia el medio ambiente, los recursos naturales, sociales y humanos, a su vez, representa para la empresa una inversión que repercute en beneficios financieros. Según González (2005), esta demostrado que las inversiones en asuntos de responsabilidad social, en algunos casos, a corto plazo y en otros a mediano plazo recupera la inversión, y a largo plazo no solamente será recuperada, sino que a su vez, la empresa genera condiciones favorables para minimizar los impactos negativos que le producen perdidas.

Actuar con responsabilidad social, produce beneficios que se reflejarán de forma casi inmediata favoreciendo la productividad y la eficiencia. Las empresas comprometidas con responsabilidad social experimentan importantes beneficios, tantos cuantitativos como cualitativos. Según Gismera y Vaquero (2000), estos beneficios se pueden dividir en beneficios externos e internos. Los principales beneficios externos según las autoras que genera para la empresa son: a) Mejora la marca e imagen: La participación social de una empresa crea una imagen y estas, están preocupadas para que esta imagen sea una imagen positiva. Fre- 
La responsabilidad social en la industria farmacéutica del estado Zulia Urdaneta, Mary Josefina

cuentemente los consumidores se sienten mas inclinados adquirir bienes y servicios de empresas que tienen una buena reputación en las áreas relacionadas con la responsabilidad social. Una empresa socialmente responsable puede beneficiarse de su reputación empresarial, incrementando así la habilidad de la empresa para atraer capitales. b) Fortalecimiento e incremento en las ventas: Cuando los clientes conocen las prácticas socialmente responsable de la empresa, que respetan los derechos de los trabajadores, la comunidad y el medio ambiente, gozan de preferencia de los consumidores. c) Desarrollo Sustentable: La responsabilidad social surge como un reflejo de cambio de paradigma que ha supuesto la aceptación universal del principio de desarrollo sostenible. Fruto de la necesidad de redituar la relación naturaleza sociedad surgió en concepto de desarrollo sostenible, cuya formulación más aceptada es la de las naciones unidas: "la satisfacción de las necesidades de la presente generación, no debe menoscabar el derecho de las futuras generaciones a satisfacer sus propias necesidades". Se ha enfatizado, así una concepción del desarrollo sostenible como el espacio de encuentro de tres vectores dinámicos Económico, Ambiental y Social, que lejos de entrar en contradicción unos con otros deben apoyarse y reforzarse mutuamente. La racionalidad de este enfoque no es otra cosa que la consideración de que la apuesta coherente que han realizado algunas empresas por la responsabilidad social, basada en sólidos códigos de conducta es positiva para la viabilidad de la empresa a largo plazo. d) Legitimidad social: Toda organización si quiere ser legitima, no puede ni debe ignorar, que en la sociedad en la que actúa se ha alcanzado u grado determinado de conciencia moral, que se refiere a los derechos que es preciso respetar.

Entre las ventajas internas destacan: a) Mejora de la gestión de los recursos humanos: Las iniciativas empresariales que contribuyen con los trabajadores, estimulan la productividad, por cuanto los programas de ayuda e incentivo a los trabajadores disminuyen los casos de estrés y depresión; además incrementa la lealtad, la motivación (los empleados están motivados serán más eficientes), y el compromiso por parte del personal. b) Reducción de los costos operativos: Diversas iniciativas logran reducir los costos significativamente reduciendo gasto e improductividad. c) Facilidad para obtener capital: Actualmente las empresas socialmente responsables están siendo evaluadas por los inversionistas para ser beneficiarias de programas de financiamientos y receptores de nuevas inversiones. d) Mejora la gestión financiera: Al lograr la reducción de los costos operativos, el incremento en las ventas y el incremento de la productividad de los trabajadores, se traduce un aumento de la rentabilidad y mejora en la gestión de tesorería.

En pocas palabras la responsabilidad social produce reducción de costos operativos, mejora la imagen de la marca en el mercado y logra mayor identidad y sentido de pertenencia de sus colaboradores, lo que se convierte en el mejor negocio, no con visión cortoplacista, también a futuro. En este sentido, Gismera y 
Vaquero (2000), concluyen que las empresas son éticas porque es rentable ser ético.

\section{Los grupos implicados en la actividad empresarial los "stakeholders"}

Éste es un enfoque complementario que nos permite avanzar sobre el sentido de la responsabilidad social de la empresa, concretando los grupos que están afectados por la actividad y con los cuales mantiene de algún modo relaciones.

Como se mencionó anteriormente la teoría de Milton Friedman ha servido como punto de partida, en cuanto a la evolución del concepto de responsabilidad social y sus grupos involucrados. En efecto estos grupos afectados por la acción empresarial han sido denominados los "Stakeholders", para contraponerlo a los "Stockholders". Estos últimos son los propietarios del capital, aquéllos ante quienes únicamente los directivos deberían sentirse responsable según el enfoque de Friedman. El cambio de los Stockholders a los Stakeholders supone ampliar el abanico de grupos ante los cuales la empresa es responsable (Camacho, 2002).

Literalmente el término Stakeholders podría ser traducido por "El depositario de una apuesta", por alguien que tiene "interés" en que el juego se lleve a efecto, porque, de alguna manera algo siempre gana (Argandeña et al., 1997).

Es evidente que los primeros "depositarios" interesados en la buena marcha de la empresa son y fueron, tradicionalmente sus accionistas e inversores, es decir lo que han arriesgado sus recursos.
Sin embargo en un modelo ampliado de las organizaciones es necesario ver a los otros miembros involucrados, como si también tuvieran intereses (de hecho los tienen) más o menos similares a los accionistas, auténticos promotores de la edificación empresarial.

Es importante aclarar lo que traduce el concepto Stakeholders, que desde su primera aparición, ha sufrido una interesante evolución, en las obras de ética empresarial, según lo señala Camacho (2002), en su origen significó "aquellas personas o grupos con los que la empresa esta implicada", esto aunque significaba un gran avance en la ética empresarial tenia una limitación importante: se consideraban los grupos que podían ser afectados por la empresa, pero que al mismo tiempo eran capaces de afectarla también a ella los resultados económicos; omitiendo aquellos grupos afectados incapaces de hacer llegar su reivindicación a la empresa. Todo esto a representado una evolución sobre la responsabilidad social de la empresa ampliando su campo hacía aquéllos que están implicados con la empresa, tanto si pueden influir sobre ella como si no. Esta consideración no excluye la responsabilidad que la empresa tiene con sus propietarios. La obtención de beneficios es, además un indicador de buena salud económica: Indica que la empresa es económicamente viable y por tanto puede hacer frente a sus compromisos no sólo de los accionistas, sino también de los grupos de interés.

Es necesario enumerar a todos aquellos grupos que merecen la consideración de Stakeholders, una vez reco- 
La responsabilidad social en la industria farmacéutica del estado Zulia Urdaneta, Mary Josefina

nocida la responsabilidad que tiene con los accionistas, indicando los problemas éticos que pueden plantearse en la relación de la empresa con cada uno de ello. En este sentido Camacho (2003:31) reconoce:

Trabajadores: Es el grupo en el que se plantean más asuntos y más complejos. Usualmente se prestaba especial atención a dos puntos: la retribución y las condiciones físicas en que se desarrollaba el trabajo. Hoy día aunque eso dos aspectos no han perdido vigencia, se ha añadido otras dos más. La primera es la participación del trabajador en la empresa, más allá de la mera actividad productiva, de forma que éste ponga en juego todas sus potencialidades humanas. Una segunda cuestión es todo lo relativo a contratación, despido y promoción del trabajador dentro de la empresa, lo que hoy en día se conoce como gestión de los recursos humanos.

Consumidores: La razón de ser de la empresa son los consumidores; por eso es esencial plantear cómo se articulan los intereses económicos de la empresa con las demandas de sus consumidores. Razón por la cual conceptos como los derechos del consumidor y la soberanía del consumidor son aquí claves. Y no menos interés ético suscita la publicidad, como forma de comunicación entre la unidad de producción y el destinatario final de lo producido.

Competidores: Se plantean aquí delicadas cuestiones que afectan el juego limpio en el mercado. Competir tiene sus límites y sus reglas. El secreto profesional y el uso de la información privilegiada son cuestiones que hoy preocupan especialmente en este terreno.
Administración Pública: A diferencia de los anteriores este suele ser un tema que encuentra menos eco entre quienes se ocupan de la ética empresarial. Existe una falta de sensibilidad notable a las obligaciones del sector productivo, vía impuestos o cotizaciones sociales. La empresa siempre adopta una actitud defensiva ante el estado, como si se tratara de una instancia que sólo amenaza con reducir sus márgenes de libertad o ganancias. Si el estado es responsable de corregir las desigualdades sociales, ha de recurrir ante las instituciones dónde se genera la renta, y si tiene que garantizar cierto nivel de cobertura de las necesidades básicas, necesita también detraer una parte de la renta que se produce en la actividad empresarial.

Entorno geográfico y humano más inmediato: Hoy son muchas las empresas que funcionan según parámetros multinacionales, y se preocupan menos del entorno inmediato que les rodea. Pero aun éstas no pueden olvidarse de la realidad más cercana, ni ignorar sus eventuales obligaciones, o al menos las oportunidades que pueden ofrecer, para crear empleo. Tampoco puede eludir su responsabilidad en relación con el entorno natural, ni olvidar los perjuicios que puedan derivarse de su actividad para con el medio ambiente.

Medio ambiente: La globalización económica, el crecimiento demográfico de la humanidad y los hábitos de consumo, están impactando el medio ambiente de forma alarmante, porque amenaza a lo que constituye el entorno necesario para la vida humana y no humana en el planeta. Los movimientos ecologistas cuestionan el modelo del desarrollo económico y 
culpan especialmente al mundo empresarial de que movido por el afán del lucro estaría sacrificando el futuro de la humanidad. Por lo que es absolutamente necesario el compromiso ético de las empresas: y se han dados pasos decisivos desde una nueva manera de entender la empresa, integrada con los sistemas naturales y dispuestos a considerar y valorar los flujos de energía y cambios estructurales que se producen en su intercambio con la naturaleza.

La riqueza de instituciones que proporciona el enfoque stakeholder lleva a un modelo de empresa de basa ampliada, abre también la puerta a una reflexión seria sobre los aspectos éticos de la gestión empresarial.

Es importante reconocer la posibilidad del conflicto de intereses. En efecto los intereses de los distintos Stakeholders, aunque sean en sí legítimos no siempre son compatible. La verdadera tarea de la ética empresarial y particularmente de la gestión ética, es poner en marcha procedimientos que permitan resolver tales conflictos de manera habitual (Camacho, 2003).

De estos grupos de intereses surgen una serie de cuestiones cuya resolución implica directa o indirectamente una perspectiva ética. Es decir cada uno de los Stakeholders en su relación con la empresa es fuente de problemas éticos, en una interminable sucesión de casos.

Es justamente en la relación de la empresa con estos grupos, el génesis de los problemas éticos empresariales, donde se busca describir los elementos de responsabilidad social presentes.

\section{Análisis e interpretación de los resultados}

En el desarrollo del estudio se procedió a la elaboración de un instrumento tipo escala Lickert dirigido a los gerentes / directores de la industria farmacéutica del estado Zulia, planteando una serie de afirmaciones o juicios, antes los cuales se pidió la reacción de los sujetos encuestados. A las afirmaciones o juicios se les otorgaron distintas direcciones, algunos con una dirección positiva y otros con direcciones negativas. Si la afirmación es positiva significa que califica favorablemente al objeto de actitud, y cuando más de acuerdo esté con la afirmación, su actitud será más favorable. En caso de la afirmación negativa significa que califica desfavorablemente al objeto de actitud, y cuanto más de acuerdo estén los sujetos con la afirmación, su actitud es menos favorable. Para el diseño de éste, los objetivos de la investigación se constituyeron en la base para la elaboración del mismo.

Al ser procesados los reactivos bajo esta escala se utilizó el criterio propuesto por Ferrer (2001) en cual consiste: en caso de que los sujetos respondan Totalmente de Acuerdo o De acuerdo esas respuestas reflejaran presencia del componente ético, salvo en aquellos casos donde las preguntas son realizadas con negación. En el caso de los ítems con respuesta ni de acuerdo ni en desacuerdo, en desacuerdo, y muy en desacuerdo, se considera la ausencia del componente ético, salvo en los casos antes descritos.

Al asumir esta tendencia se utilizó la moda como medida estadística, por tratarse de una variable de carácter cuali- 
La responsabilidad social en la industria farmacéutica del estado Zulia Urdaneta, Mary Josefina

tativo, y al cambiar la denominación hacía presencia y ausencia del componente ético, se pasa de un nivel de medición ordinal a uno nominal, reduciendo así el nivel de medición, donde sólo se justifica el uso de la moda (Parra, 2000).

El tratamiento estadístico se hizo utilizando la estadística descriptiva, dedicada a detallar y analizar grupo de datos, estos fueron representados en forma de frecuencias (Fr) y porcentajes (\%), obteniendo tablas de interés para el estudio.

En este segmento se describen los elementos de responsabilidad social identificados por la industria farmacéutica en relación con los grupos de interés interno y externo, lo que algunos autores denominan "Depositarios" o su versión norteamericana los "Stakelholders".

\subsection{Relación Empresa-Grupos de Interés Internos}

Dentro de los grupos de interés internos se puede identificar los empleados, accionistas y directivos. En relación con este grupo de interés los resultados evidencian que solo un $33 \%$ de las empresas entrevistadas buscan generar un impacto positivo en su entorno y posee los mecanismos para lograrlo y además esta dispuesta apoyar alguna causa social, pero le falta imprimirle un principio de acción, ya que en ocasiones no sabe como intervenir. El porcentaje restante $(67 \%)$ se mostró en descuerdo con los aspectos analizados.

En cuanto al compromiso con sus trabajadores según los datos resumidos en el gráfico 1, se observó que en las empresas del sector existe un verdadero compromiso con trabajadores, evitando las prácticas discriminatorias, garantizando igual trato y oportunidad a sus empleados, proporcionando compensaciones justas, que mejoren la calidad de vida de sus empleados. Las empresas encuestadas mantienen una comunicación con sus empleados y comparte con ellos información dentro de los límites legales y de los condicionamientos de la competencia. Es importante destacar que de los resultados obtenidos se puede inferir que las empresas del sector han entendido la importancia del recurso humano para el desarrollo exitoso de las actividades empresariales. En los aspectos relacionados con la educación, capacitación y salubridad, las empresas capacitan y están dispuestas a capacitar a sus trabajadores en las áreas de su interés y en el manejo de nuevos equipos y técnicas productivas; lo que demuestra el interés de las empresas mantener en sus instalaciones personal altamente capacitado y con un alto sentido de pertenecía.

En cuanto al tema de salubridad y seguridad en el lugar de trabajo, los resultados muestran una realidad que pudo ser observada en las visitas a las empresas y consiste en que los trabajadores están debidamente instruidos y concientizados sobre la seguridad y salubridad en el lugar de trabajo. Además son protegidos contra accidentes y enfermedades laborales.

Al estudiar los temas de motivación y participación en la organización, se buscaba identificar aquellas políticas y actividades realizadas que llevaran a una mayor satisfacción del trabajador con su centro de trabajo más allá de su relación salarial, actividades sociales, de reconocimiento y comunicación con el trabajador, integración con la familia del trabaja- 
dor, entre otras. En cuanto al tema de comunicación interna las empresas encuestadas difunden entre sus miembros sus políticas y estrategias a través de reuniones que son convocadas permanentemente.

En relación con el tema de reconocimiento el $67 \%$ promueve y premia anualmente a sus trabajadores y un $33 \%$ hace reconocimiento público a los trabajadores promovidos, las empresas manifestaron que este tipo de reconocimiento es uno de los más apreciados por los trabajadores. En cuanto a las actividades de integración con sus familias propiciadas por la empresa, la mayoría manifestó, no realizar este tipo de actividades y una de las actividades más frecuentes son las actividades sociales y deportivas, según se evidencia en el Gráfico 1.

Un sector importante dentro de los grupos internos son los accionistas, en este sentido el $67 \%$ de las empresas encuestadas evidencia atender debidamente las solicitudes realizadas por los mismos y le proporcionan información relevante. Es importante destacar que la mayoría de las empresas (67\%), considera que sus directivos ofrecen una gestión diligente y eficiente a fin de asegurar un rendimiento justo y competitivo a sus inversionistas. Un aspecto importante es que un 33\% manifiesta no tener una relación armoniosa con los accionistas (Gráfico 2).

La actividad de la empresa implica relaciones humanas; se trata de equilibrar los intereses razonables de aquellos involucrados en los procesos (Stakeholders). En este sentido, en el ámbito de la gestión de recursos humanos el Libro Verde - Unión Europea (2001) propone a las empresas:

a) Medidas que incluyan el aprendizaje permanente, la responsabilización de los trabajadores, la mejora de la información en la empresa, mayor equilibrio entre trabajo, familia y ocio, la igualdad de retribución y de perspectiva profesionales para las mujeres, la participación en los beneficios de la empresa y la consideración de la capacidad de inserción profesional y la seguridad en el lugar de trabajo.

\section{Gráfico 1. Elementos de Responsabilidad Social. Grupo de Interés interno. Empleados.}

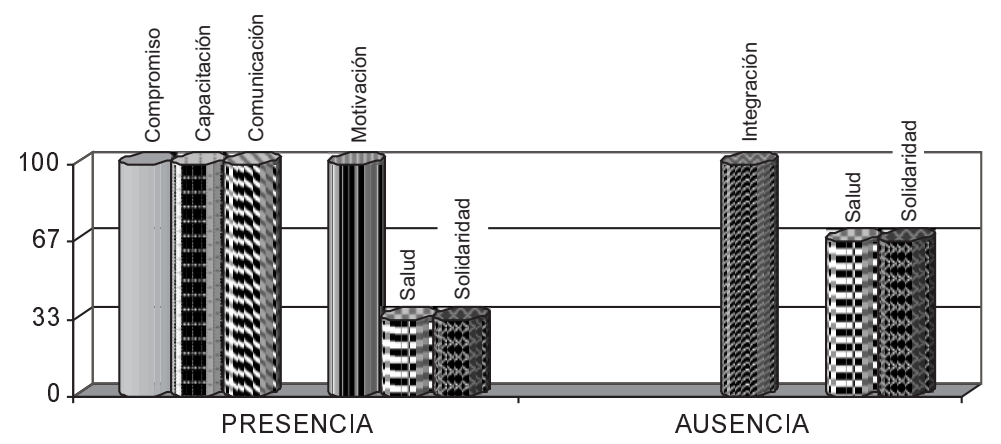

Fuente: Elaboración propia 2006. 


\section{Gráfico 2. Elementos de Reponsabilidad Social. Grupo de Interés interno. Accionistas.}

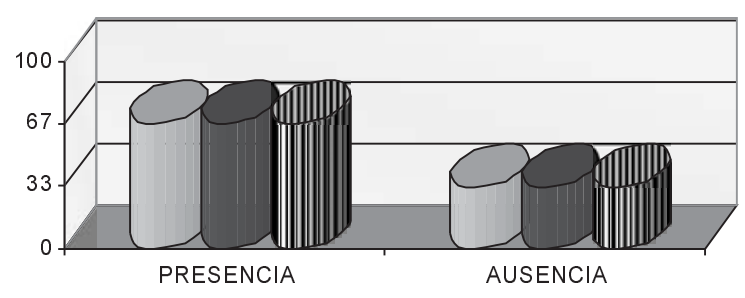

$$
\square \text { Rendimiento } \square \text { Atención } \quad \text { Il Información }
$$

Fuente: Elaboración propia 2006.

b) Prácticas responsables de contratación que faciliten, la contratación de personas pertenecientes a minorías étnicas, trabajadores de mayor edad, mujeres desempleadas y personas desfavorecidas.

Así pues, en concordancia con lo establecido en el Libro Verde las empresas del sector farmacéutico del estado Zulia evidencian el cumplimiento de las garantías constitucionales y laborales. Además, se encuentran presentes con mayor fuerza en la industria en relación a los grupos de interés internos, los siguientes elementos de responsabilidad social.

\section{Empleados:}

La conducta del empresario respecto a los hombres que forman parte de la empresa, ha de basarse en la consideración de la dignidad humana, en tal sentido se reconocer los siguientes elementos de responsabilidad social presentes en la industria en relación a este grupo.

- Niveles de remuneración justas

- Respeto hacía el individuo, no discriminación de raza, color, creencia en la aplicación de las políticas.
- Condiciones de trabajo seguras y saludables

- Capacitación y adiestramiento

- Promoción y reconocimiento

- Buena comunicación interna y el manejo de la información

Socios y Accionistas:

Las empresas deben entender que las aportaciones de los socios son elementos imprescindibles para el desarrollo de la propia empresa y que los accionistas asumen los riesgos de la propiedad. Entre los elementos presentes se destacan:

- Protección de los intereses de los accionistas

- Mantener informados a los accionistas de los principales sucesos que afectan la empresa

- Atención oportuna de las solicitudes, sugerencias y reclamaciones de los accionistas.

- Rendimientos justos y competitivos a los inversionistas.

\subsection{Relación Empresa-Grupos de Interés Externos}

En este aparte se analizó de qué manera se relaciona la empresa con su 
entorno, es decir, frente a los grupos de interés externo, de los cuales se puede identificar los clientes, proveedores, comunidades locales, competidores, Estado, el medio ambiente y la sociedad en general. En este análisis se trató de diferenciar la naturaleza de las políticas de proyección social: a) las empresas con políticas activas, es decir, aquellas que buscan deliberadamente generar un impacto positivo en su entorno y tienen un mecanismo formal dedicado a alcanzar dichos objetivos; b) las que presentan políticas pasivas, es decir aquellas empresas dispuestas apoyar alguna causa pero que no saben como hacerlo y prefieren no invertir en organizar y esperan a reaccionar en función de la demanda (Benavides, 2001).

Los elementos presentes en la industria farmacéutica con relación a este grupo de muestran los siguientes resultados: En relación con las comunidades, según se observa en el Gráfico 3 las empresas se inclinan apoyar primordialmente lo relacionado con la salud, educación y seguridad de las comunidades en su entorno. El $67 \%$ destina recursos financieros y humanos para las actividades de integración con la comunidad y un $33 \%$ promueve el desarrollo continuo de las misma y es líder en la preservación y mejora del medio ambiente, en este sentido es importante destacar que se observa poca participación de las empresas del sector en las actividades de preservación y conservación del medio ambiente y los recursos de la tierra; solo un 33\% manifestó que la causa social principal es el resguardo del medio ambiente el resto $(67 \%)$, no tiene una política definida para el medio ambiente y su entorno.

Un aspecto importante que se relaciona en forma indirecta con las comunidades es que la empresa según se deduce de la información suministrada, paga oportunamente sus obligaciones fiscales, dado que el $100 \%$ manifestó no haber recibido multas de ningún organismo oficial por incumplimiento de sus obligaciones, lo que atendiendo a lo establecido en la Constitución de la República Bolivariana de Venezuela en los artículos No. 133 y 316 referidos al pago de los impuestos y a

\section{Gráfico 3. Elementos de Responsabilidad Social. Comunidades y Ambiente}

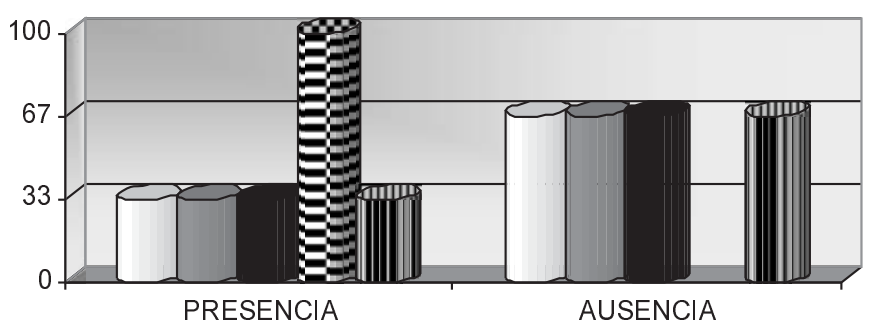

$$
\begin{aligned}
& \square \text { Recursos } \square \text { Desarrollo } \quad \text { Preservación ambiente } \\
& \text { Salud, Educación y Seguridad } \quad \text { Integración }
\end{aligned}
$$

Fuente: Elaboración Propia 2006. 
La responsabilidad social en la industria farmacéutica del estado Zulia Urdaneta, Mary Josefina

la justa distribución de las cargas públicas respectivamente, coadyuva al Estado a elevar el nivel de vida de la población. Es decir, las empresa vía impuestos, contribuye en forma indirecta a mejorar las condiciones del entorno y elevar la calidad de vida de la población. La sociedad espera de la empresa unos beneficios de diversos tipos, en correspondencia a los servicios que la propia sociedad presta a la empresa.

Es menester destacar que el $67 \%$ de los entrevistados manifestó no destinar recursos financieros a las actividades de integración con la comunidad y sólo el $33 \%$ de los encuestados manifiesta no mantener vínculos con las asociaciones de vecinos. Es decir, se evidencia que existe un vínculo entre las empresas y las asociaciones de vecinos, pero las empresas no han definido políticas que permitan el desarrollo pleno de esas relaciones. Las políticas en el sector no están enfocadas hacia el ambiente físico, sino a

\section{Gráfico 4 \\ Elementos de Responsabilidad Social. Proveedores}

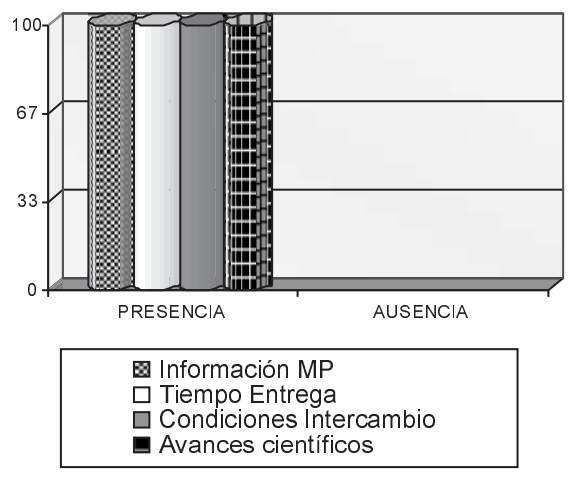

Fuente: Elaboración Propia 2006. mejorar los niveles de salud, educación y seguridad de las comunidades vecinas.

En relación con los proveedores, según se evidencia en el Gráfico 4, éstos ofrecen condiciones que le permite a las empresas brindar a sus clientes productos y servicios de mayor calidad y con mejores condiciones de pago. Los proveedores son un elemento clave en la cadena de comercialización, mantener excelentes relaciones como se evidencia garantiza en gran medida el éxito del negocio. Se pueden observar en estas relaciones que se respetan los tiempos de entregas, y las condiciones de intercambios.

Con relación a los competidores las empresas se muestran convencidas de la importancia de las asociaciones empresariales del sector para facilitar intercambios y acuerdos, sin embargo estas asociaciones se muestran debilitadas ya que no acuerdan distribuir el mercado atendiendo a los intereses compartidos, y un $67 \%$ manifestó no realizar acuerdo en a cuanto a política empresariales para regular la competencia y el desarrollo sectorial. Es importante destacar que esta situación puede ser consecuencia del tamaño de las industrias del sector que se halla en la región Zuliana.

En relación a los clientes, consumidores y usuarios existe una actitud de colaboración, según se establecen en el Gráfico 5, donde se muestra que los elementos analizados están presentes en la industria en un 100\%; lo que favorece las relaciones empresa-clientes.

Según información suministrada por los gerentes los clientes reciben en las cantidades y especificaciones requeridas sus pedidos, y las empresas del sector adecuan sus procesos para res- 


\section{Gráfico 5 Elementos de Responsabilidad Social. Clientes}
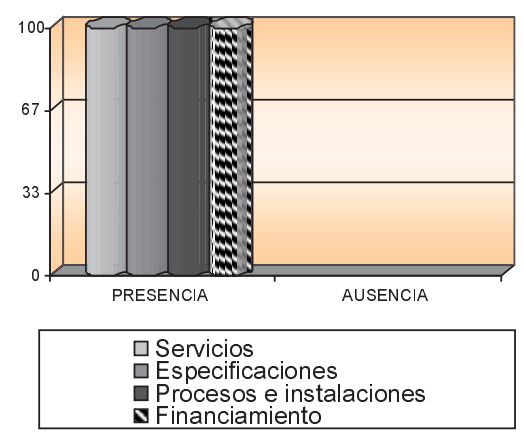

Fuente: Elaboración Propia 2006.

ponder de manera óptima con las especificaciones solicitadas y además ofrece planes de financiamiento a corto plazo a sus clientes y los mismos cumplen fielmente sus compromisos. Lo que evidencia que las relaciones mutuas son de servicio y confianza y que empresas están conscientes de la importancia que este grupo tiene en el mantenimiento sostenible de las mismas.

La visión integral de la empresa responsable incluye un modo de actuar que no sólo se debe aplicar a las políticas internas de la empresa, sino que debería proyectarse también hacia clientes, proveedores y accionistas (Benavides, 2001). En este sentido resulta interesante conocer el compromiso que la empresa mantiene con sus clientes y proveedores, ya que estos son un engranaje crucial en la cadena productiva de la empresa.

Los resultados de la investigación evidencian que las empresas del sector tienen un compromiso con sus clientes. El $100 \%$ de las empresas encuestadas estructuran sus procesos a fin de cumplir en forma óptima las especificaciones y requerimientos de sus clientes. Sin embargo un aspecto característico representa el hecho de que $33 \%$ de las empresas no entrega a sus clientes oportunamente información sobre adelantos científicos, lo que puede ocasionar que la divulgación de las investigaciones no llegue pertinentemente, y se desvirtué la razón de ser de la industria en cuanto a su rol de ser proveedoras de soluciones a las necesidades de salud y bienestar de la sociedad. Cabe destacar que por tratarse de pequeñas empresas dentro de la industria farmacéutica nacional, estas poco incursionan en este tipo de procesos.

En tanto las relaciones con el Estado, es sorprendente la información de que el $67 \%$ de las empresas ha recibido algún reconocimiento por parte del Estado por las labores comunitarias, sin embargo en ese mismo porcentaje las empresas consideran que el Estado brindan poco incentivos al desarrollo de programas sociales y no ha sido posible establecer alianzas estratégicas para el adelanto de los mismos.

Del análisis anterior se puede inferir que los elementos de responsabilidad social presentes con mayor fuerza en la industria farmacéutica en relación a los grupos de interés externos son los siguientes:

\section{Comunidad}

Las relaciones empresa-comunidad son tanto más importante cuanto mayor sea la situación de mutua relación. En tal sentido se reconocer los siguientes elementos de responsabilidad social presente en la industria en relación a este grupo: 
La responsabilidad social en la industria farmacéutica del estado Zulia

Urdaneta, Mary Josefina

- La principal causa social con la que contribuye es mejorar los niveles de salud, educación y seguridad de la comunidad.

- Atiende correctamente las obligaciones fiscales, efectuando las liquidaciones que correspondan, de acuerdo a las leyes vigentes.

Medio ambiente:

La empresa tiene la obligación de mantener el equilibrio ecológico y el resguardo del medio ambiente. En este sentido se observó poca participación de la industria en el compromiso de potenciar una ecología social de trabajo.

Proveedores:

Los proveedores constituyen un elemento fundamental entre los colaboradores de la empresa y tienen unos derechos y obligaciones similares a los restantes grupos humanos y económicos que conforman el mapa de los "depositarios" de la misma (Argandoña, et al.; 1997). En relación con ellos se pueden describir los siguientes elementos de responsabilidad social presentes en la industria:

- Las relaciones se inspiran en el respeto a las condiciones que cada parte impone

- Los proveedores están comprometidos con los tiempos de entregas

- Los proveedores brindan información actualizada sobre nuevos insumos

Competidores:

La lícita competencia contribuye a garantizar la calidad de los productos y su justa relación con los precios del mercado. Por tanto favorecer las actividades económicas en lícita competencia será garantía de mayor justicia en la comercialización de los productos y de mayor transparencia en la actividad económica en general. Sin em- bargo en referencia a este grupo, no se evidencia la influencia de algunos elementos de responsabilidad social en la industria, ya que el sector se muestra poco integrado con sus competidores.

\section{Clientes:}

Sin clientes una empresa no puede sobrevivir, la empresa deberá adoptar una actitud de colaboración cuidando que las relaciones mutuas sean de servicio y confianza. En relación con este grupo se pueden identificar los siguientes elementos:

- Calidad y respeto por las especificaciones del cliente

- Servicio Post venta adecuado al tipo de producto

- Optimización de procesos para brindar un mejor servicio

- Financiamiento a corto plazo

\section{Estado:}

Siendo la responsabilidad social un pilar para el desarrollo sustentable el Estado brinda poco incentivo para el desarrollo de programas sociales en las comunidades y no establecen según se desprenden de los resultados obtenidos oportunidades de formalizar alianzas estratégicas que permitan el desarrollo de programas en beneficio de las comunidades y la sociedad en general. El único elemento de responsabilidad social que se identifica en la industrial, según los resultados obtenido es el cumplimento de las obligaciones fiscales de las empresas del sector.

Las principales prácticas de responsabilidad social identificadas en este estudio en el sector farmacéutico del estado Zulia, en relación con su grupo de interés, se resumen en el Cuadro 1. 


\section{Cuadro 1 \\ Elementos de Responsabilidad Social presentes en la Industria Farmacéutica del Estado Zulia}

\begin{tabular}{|c|c|}
\hline Grupo de Interés & Elementos de Responsabilidad Social presentes \\
\hline Empleados & $\begin{array}{l}\text { - Respeto a los derechos humanos. } \\
\text { - No discriminación laboral. } \\
\text { - Condiciones de trabajo seguras y saludables. } \\
\text { - Capacitación y adiestramiento laboral. } \\
\text { - Promoción y reconocimiento. } \\
\text { - Adecuada comunicación interna y el manejo de la información. } \\
\text { - Niveles de remuneración justas. }\end{array}$ \\
\hline Accionistas & $\begin{array}{l}\text { - Protección de los intereses de los accionistas. } \\
\text { - Mantener informados a los accionistas de los principales sucesos que } \\
\text { afectan la empresa. } \\
\text { - Atención oportuna de las solicitudes, sugerencias y reclamaciones de } \\
\text { los accionistas. } \\
\text { - Niveles de rentabilidad competitiva a los inversionistas. }\end{array}$ \\
\hline Clientes & $\begin{array}{l}\text { - Elaboración de productos de calidad } \\
\text { - Respeto a las especificaciones del cliente. } \\
\text { - Servicio Post venta adecuado al tipo de producto. } \\
\text { - Manejo de tecnología de punta. } \\
\text { - Optimización de procesos para brindar un mejor servicio. } \\
\text { - Financiamiento a corto plazo. }\end{array}$ \\
\hline Proveedores & $\begin{array}{l}\text { - Las relaciones se inspiran en el respeto a las condiciones que cada parte } \\
\text { impone. } \\
\text { - Cumplimiento de los tiempos de entrega. } \\
\text { - Los proveedores brindan información actualizada sobre nuevos insu- } \\
\text { mos. }\end{array}$ \\
\hline Competidores & $\begin{array}{l}\text { - No se evidencia en esta investigación elementos de responsabilidad so- } \\
\text { cial con relación a este grupo. Ya que el sector se muestra poco integra- } \\
\text { do con sus competidores. }\end{array}$ \\
\hline Medio Ambiente & $\begin{array}{l}\text { - No se evidencia en esta investigación elementos de responsabilidad so- } \\
\text { cial con relación a este grupo. Poca participación de la industria, en po- } \\
\text { tenciar una economía social de trabajo. }\end{array}$ \\
\hline Comunidades & $\begin{array}{l}\text { - Contribución a mejorar los niveles de salud, educación y seguridad de la } \\
\text { comunidad. } \\
\text { - Atención oportuna a las obligaciones fiscales, efectuando las liquidacio- } \\
\text { nes que correspondan, de acuerdo a las leyes vigentes. }\end{array}$ \\
\hline Estado & - Cumplimiento de las obligaciones fiscales. \\
\hline
\end{tabular}

Fuente: Elaboración propia (2006). 
La responsabilidad social en la industria farmacéutica del estado Zulia

Urdaneta, Mary Josefina

\section{Conclusiones}

Existen evidencias importantes de presencia de elementos de responsabilidad social en la industria farmacéutica en el estado Zulia, en cuanto a las relaciones con sus grupos de interés. Aunque es necesario aclarar que estas evidencias en muchos de los casos se presentan de forma implícita y no están formalizadas como prácticas de responsabilidad social.

En cuanto a los grupos de interés internos, están presentes elementos significativos de responsabilidad social, en una proporción que puede considerarse importante. Destacando principalmente lo relacionado con los recursos humanos. Los elementos identificados están relacionados principalmente con la salud ocupacional de las empresas, específicamente los relacionados con la protección del recurso humano, los elementos de seguridad social y el fomentar un buen clima de trabajo, lo que a mediano plazo aumenta la competitividad y disminuye los costes laborales.

Las empresas del sector han entendido la importancia del recurso humano para el desarrollo exitoso de las actividades empresariales; la tendencia moderna de la gestión de recursos humanos, tiende cada vez más a incorporar el concepto de que la productividad del trabajador esta relacionado con el nivel de capacitación que tenga y con cuán motivado e identificado se sienta con la empresa.

En relación con el grupo de interés externo, destacan dos de los elementos clave de la cadena de comercialización dentro del sector los clientes y proveedores. En relación con los proveedores, se evidencia que éstos ofrecen condiciones que le permite a las empresas brindar a sus clientes productos y servicios de mayor calidad y con mejores condiciones de pago, y mantienen relaciones armónica de mutua cooperación con las empresas del sector; y en cuanto a los clientes, las empresas del sector se preocupan por la calidad y el respeto a las especificaciones de los mismos. Sin embargo, estas industrias se muestran poca desarrolladas en la elaboración de nuevos productos y aunque manifiesta invertir en investigación y desarrollo, son pocos los resultados obtenidos de esas investigaciones; muchas veces los innumerable obstáculos para la adquisición de la materia prima, principalmente debido al control de cambio existente desde hace algo más de tres años; o los tramites engorrosos a lo que están obligados a cumplir dado lo delicado de su actividad, imposibilitan que se suministren desde la región nuevos medicamentos que contribuyan a mejorar la calidad de vida y a minimizar los efectos secundarios. Esto por supuesto no contribuye a la consolidación de uno de los fines sociales más importante que tiene el sector, ayudar al logro de mejores condiciones de vida a la población, además, de brindar medicamento que minimicen sus efectos secundarios; ya que esto solo es posible si las empresas invierte en investigación y desarrollo que confluya en la innovación de nuevos medicamentos.

En cuanto a la manera como se relaciona la empresa con su entorno se evidencia poca integración con las comunidades y la aplicación de una política de proyección social mixta, es decir, tiene estrategias definidas en algunos campos 
de acción, pero en otros depende de solicitudes de la comunidad o reglamentaciones gubernamentales para actuar. Las empresas vía impuestos, contribuye en forma indirecta a mejorar las condiciones del entorno y elevar la calidad de vida de la población.

Otras relaciones que se notan debilitadas en cuanto a los elementos de responsabilidad social son las referidas al sector con el Estado, no se evidencia en esta investigación presencia de elementos importante de responsabilidad social en esas relaciones.

Las practicas de responsabilidad social empresarial en Venezuela se presentan un tanto minimizadas en algunos sectores económicos no desarrollados plenamente, ya que las grandes corporaciones con presencia en otros países han importando las mejores practicas, integrándola como parte de sus principios y valores. En definitiva, la responsabilidad social constituye una ventaja competitiva que es actualmente utilizada en las empresas líderes a nivel mundial; considerándola como un activo intangible, tanto o más importante, que los demás activos dentro de la organización.

La industria farmacéutica, tiene una gran responsabilidad social que muchas veces no es entendida, ya que posee el compromiso de lograr mejores condiciones de vida para la población, a través de la preservación de la salud y alivio de los síntomas de muchos padecimientos, objetivo que sólo es posible con la existencia de programas de Investigación y desarrollo e innovación. La industria farmacéutica del estado Zulia está realizando pequeños avances en torno a la responsabilidad social; entendiendo el rol social implícito en este negocio, al ser proveedoras de soluciones a las necesidades de salud y bienestar de la sociedad, ya este compromiso obliga a las empresas del sector a mantener dentro de sus operaciones financieras o productivas, importantes elementos de responsabilidad social empresarial, como lo muestran los resultados de esta investigación. Sin embargo, es necesario que las empresas del sector identifiquen y formalicen las prácticas de responsabilidad social a fin de poder determinar sus costes y los efectos que éstos tienen en la gestión empresarial.

\section{Referencias Bibliográficas}

Argandoña, A. Cortina, A. y Otros (1997). Ética y empresa una visión multidisciplinar. Fundación Argentaria. 308 pp.

Bateman, Thomas y Snell, Scott (2001). Administración. Una Ventaja Competitiva. Mc Graw Hill. Mexico, Mexico.

Benavides, Marcela y Gastelumendi, Guida (2001). Responsabilidad social empresarial: un compromiso necesario. Universidad del Pacifico, Centro de investigación. Lima, Perú. (On Line). Disponible en línea. http.//www. http://www.iadb.org/etica . (Consulta: 2003, Julio 31).

Bonomi, Gonzalo; Brennan, Luis; Valera, Pablo (2003). La responsabilidad Social Empresarial en el Marco de las Relaciones Laborales. (On line). Disponible en www.ilo.org/public/spanish/region/ampro/cinterfor/temas/ employer/respons.htm (Consultada: 2005, Noviembre, 15).

Camacho, Idelfonso; Fernández, José y Miralles, Josep (2002). Ética de la empresa. RGM. Bilbao. 
La responsabilidad social en la industria farmacéutica del estado Zulia

Urdaneta, Mary Josefina

Cortina, Adela (2003). Las virtudes cívicas de la RSE. Ponencia presentada en el Seminario Internacional de responsabilidad social empresarial. Santiago de Chile, Chile. (On line). Disponible en http.//www.prohumana.cl. (Consultada: 2003, Julio, 31).

Fernández, Javier y Otros (2001). La ética en Ios negocios. Editorial Ariel. Barcelona, España. 262 pp.

Ferrer, Juliana (2001). Presencia del componente ético en sectores de la actividad industrial. Ediciones Astro Data. Maracaibo. Venezuela.

FUNDEMAS (Fundación Empresarial para la Acción Social) 2004. "Responsabilidad Social Empresarial en El Salvador.

Gismera, Lura y Vaquero, María (2000). La responsabilidad social de la empresa en España: la acción social. Papeles de Ética, Economía y Dirección, No. 5, 2000. (On line). Disponible en http.//www.iadb.org/ética (Consultada: 2003, Julio, 31).

Gitman, Lawrence y Mcdaniel, Carl (1995). EI mundo de los negocios. Harla, S.A. México.

González, Tito (2005). La responsabilidad social de la empresa, un buen negocio. Perú: Ilustrados.com, 2005. p 11. (On line) disponible en http:// site.ebrary.com/lib/bibliotecaserbiluz/ Doc?id=10092936\&ppg=11. (Consultada: 2003, Mayo, 25).

González, M.J. Lo Ético en la Historia del Pensamiento Económico. Información comercial española. Marzo. Páginas 17-30.
Goodstein, Leonard y Otros. (2000). Planificación estratégica aplicada. Mc Graw Hill. Santa fe de Bogota. Colombia.

Jonas, Hans (1995). El principio de Responsabilidad. Editorial Herder. Barcelona. España.

Jones, Aura (2001). Hacia una mejor compresión de la responsabilidad social corporativa. (On - Line). Disponible en: http://www.iadb.org/etica (Consulta: 2003, Junio, 15).

Kliksberg, Bernardo (2003). Hacia una economía con rostro humano. Ediciones Astro Data. Maracaibo. Venezuela. $175 \mathrm{pp}$.

Libro Verde de la Comisión Europea (2001). Fomentar un marco europeo para la responsabilidad social de las empresas.

Morros, Jordi y Vidal, Isabel (2006). Responsabilidad Social Corporativa. FC editorial. Madrid. España.

Ortiz, José (1995). La hora de la ética empresarial. Mc Graw Hill / Interamericana de España. Madrid. España.

Ortíz, María (2006). Bioética para una salud pública con responsabilidad social. Chile: Red Acta Bioethica, 2006. p 12. (On line). Disponible en: http:// site.ebrary.com/lib/bibliotecaserbiluz/ Doc?id=10116204\&ppg=12 (Consultada: 2006, Junio, 15).

Parada, José (2003). Finanzas: Su dimensión Ética. Ediciones gestión 2000. Barcelona. España. 105 pp.

Schavarstein, Leonardo (2002). La inteligencia social de las organizaciones. Desarrollando las Competencias Necesarias para el Ejercicio Efectivo de la Responsabilidad Social. Paidós. España. 274 pp. 